\title{
SIMULASI PEMILAH BENDA BERDASARKAN WARNA (HITAM- PUTIH) MENGGUNAKAN SENSOR WARNA BERBASIS MIKROKONTROLER AT89S51
}

\section{Simulation To Separate Thing Base On Color (Black-White) Using Color Sensor Based On Microcotroller AT9S51}

\author{
Sandi apriandi, adadajah28@gmail.com ${ }^{1)}$,Mohamad Amin HD, amin123@ batan.go.id ${ }^{2)}$, \\ Sri Dianing Asri, s_dianing@ yahoo.com ${ }^{3)}$ \\ 1)2)3) Jurusan Sistem Komputer,STMIK Indonesia
}

\begin{abstract}
At present the company is always trying to replace the work done by humans, replaced by machines in order to improve the efficiency and quality of production. In other words, many companies automate their production. For example, production processes that were initially carried out manually as in the process of sorting their products. In the industry this process is done manually with human effort and requires a large amount of labor and makes the production process longer. To overcome this problem, companies that want more effective and efficient production processes to change production patterns by applying automation in their production systems. This is realized by the construction of a packing system for goods, where the system usually consists of goods distribution in the form of a mechanical conveyor system and packaging of goods. As in the case of items based on the color sorting system, you will need a tool that can automatically sort this product. This system consists of object sensors, color sensors, conveyor belts, and means of dividing goods. Mechanical systems are built using acrylic, plastic and PVC. The control system in this simulation uses the AT89s51 IC microcontroller.
\end{abstract}

Keyword : Augmented Reality, Satya Negara Indonesia University, Virtual Reality, 3D

\begin{abstract}
ABSTRAK
Saat ini perusahaan selalu berusaha untuk menggantikan pekerjaan yang dilakukan oleh manusia diganti dengan mesin dalam rangka meningkatkan efisiensi dan kualitas produksi. Dengan kata lain banyak perusahaan mengotomatisasi produksi mereka. Sebagai contoh, produksi proses yang pada awalnya masih dilakukan secara manual seperti dalam proses penyortiran barang produksinya. Dalam industri Proses ini dilakukan secara manual dengan usaha manusia dan membutuhkan jumlah tenaga kerja yang tidak sedikit dan membuat proses produksi menjadi lebih lama. Untuk mengatasi masalah ini, perusahaan yang ingin proses produksi yang lebih efektif dan efisien untuk mengubah pola produksi dengan menerapkan otomatisasi dalam sistem produksi mereka. Hal ini diwujudkan dengan pembangunan packing unit sistem barang, dimana sistem ini biasanya terdiri dari pasokan distribusi barang dalam bentuk sistem conveyor mekanis dan kemasan barang. Seperti dalam kasus barang berdasarkan sistem warna penyortiran akan membutuhkan alat yang dapat memilah produk ini secara otomatis. Sistem ini terdiri dari sensor objek, warna sensor, conveyor belt, dan sarana membagi barang. Sistem mekanis adalah dibangun menggunakan bahan akrilik, plastik dan pvc. Sistem kontrol dalam simulasi ini menggunakan AT89s51 mikrokontroler IC..
\end{abstract}

Kata Kunci: Augmented Reality, Universitas Satya Negara Indonesia, Virtual Reality, 3D

\section{PENDAHULUAN}

Dewasa ini perusahaan selalu berupaya untuk mengganti pekerjaan yang selama ini dilakukan oleh manusia untuk digantikan dengan mesin-mesin dalam rangka efisiensi dan peningkatan kualitas produksinya. Dengan kata lain banyak 
perusahaan melakukan otomasi produksinya. Misalnya, proses produksi yang pada awalnya masih dilakukan secara manual seperti pada proses penyortiran. Pada proses industri manual dikerjakan oleh tenaga manusia dan membutuhkan jumlah tenaga kerja yang tidak sedikit dan membuat waktu proses produksi menjadi lebih lama. Selain itu sering terjadi human error pada industri manual ini karena melakukan pekerjaan secara berulangulang. Untuk mengatasi masalah itu, perusahaan yang menginginkan proses produksi yang lebih efektif dan efisien melakukan perubahan pola produksi dengan mengaplikasikan sistem otomasi dalam produksinya. Hal ini diwujudkan dengan pembangunan unit system penyortiran barang, dimana biasanya sistem ini terdiri atas perlengkapan distribusi barang yang berupa conveyor dan sistem mekanik pembungkus barang. Seperti halnya dalam memilah barang berdasarkan warna yang berbeda akan membutuhkan suatu alat yang bisa memilah produk-produk tersebut secara otomatis. Dengan adanya mikrokontroler dapat dimanfaatkan sebagai pengolah data dari sensor dan menjadikannya suatu tampilan akhir dalam proses pemilah barang. Otomatisasi akan sangat membantu dalam proses produksi produk-produk tersebut. Dengan perkembangan teknologi mikrokontroler dan komputer masalah pengendalian elektronis menjadi semakin mudah.

Dari berbagai permasalahan di atas penulis mencoba untuk bereksperimen dengan cara menuangkan ide melalui sebuah karya teknologi yang kiranya dapat menjawab ataupun mengurangi beban permasalahan tersebut. Dari alat yang akan diberi nama "Simulasi Pemilah Benda Berdasarkan Warna (Hitam dan Putih)" ini kiranya dapat mengurangi beban karyawan perusahaan yang bekerja di bagian sorting barang. Alat ini juga diharapkan dapat mempermudah bagi kalangan akademisi dalam mempelajari sistem otomasi yang bisa diterapkan di industri.

Definisi dan pengertian mengenai sebuah conveyor atau pemilah suatu benda yang di sampaikan oleh para ahli mekanik untuk dapat menjelaskan makna dari sebuah conveyor / pemilah suatu benda.

Belt Conveyor adalah peralatan yang cukup sederhana yang digunakan untuk mengangkut unti atau curah dengan kapasitas besar. Alat tersebut terdiri dari sabuk yang tahan terhadap pengangkutan benda padat. Sabuk yang digunakan pada belt conveyor ini dapat dibuat dari berbagai jenis bahan. Misalnya dari karet, plastik, kulit ataupun logam yang tergantung dari jenis dan sifat bahan yang akandiangkut. Untuk mengangkut bahan -bahan yang panas, sabuk yang digunakan terbuat dari logam yang tahan terhadap panas.

Mikrokontroler berfungsi sebagai pusat pengendali dan sebagai pengambil keputusan dari data-data yang dikirimkan oleh sensor-sensor. Mikrokontroler yang digunakan pada robot ini adalah Atmel AT89S51.

\section{Beberapa alasan utama pemilihan mikrokontroler Atmel AT 89S51:}

1. Harganya yang relatif murah

2. Kecepatan sampai dengan frekuensi clock $33 \mathrm{MHz}$.

3. Cocok untuk produk $\mathrm{MCS}^{\circledR}-51$.

4. Jumlah port I/O sebanyak 32 buah,

5. Mempunyai In-System Programmable (ISP) sebesar 4K Byte dengan batas penulisan dan penghapusan program sampai dengan 1000 kali.

6. Memiliki RAM Internal sebesar $128 x 8$ bit

7. Rentang tegangan (Vcc) yang digunakan antara $4.0-5.5$ volt tetapi umumnya menggunakan level tegangan 5 volt

\section{Fitur-fitur lain yang dimiliki Atmel AT 89S51 adalah:}

1. Memiliki Timer/Counters sebesar $2 \times 16$ bit.

2. Mempunyai 6 buah sumber Interrupt.

3. Terdapat Low-power Idle dan Powerdown Modes. .

4. Adanya Interrupt Recovery pada kondisi Power-down Modes.

5. Memiliki Watchdog Timer.

6. Memiliki Dual Data Pointer.

7. Terdapat Power-off Flag. 
8. Kemasan fisik 40 pin.

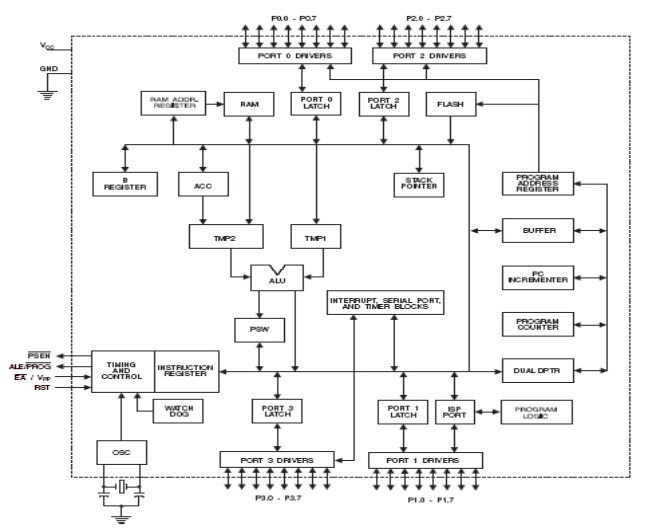

Gambar 1. Diagram blok AT89S51

Arsitektur perangkat keras AT89S51 memadukan arsitektur perangkat keras keluarga mikrokontroler 8051 (MCS-51) dan teknologi Flash Memory. Arsitektur keluarga 8051 menggunakan modifikasi arsitektur Harvard dengan alamat terpisah untuk memori program dan data. Memori untuk program bisa dialamati hingga $64 \mathrm{~K}$. Memori bawah (4K, $8 \mathrm{~K}$ atau $16 \mathrm{~K}$ tergantung tipe) bisa terletak di chipnya. Mikrokontroler ini memiliki 128 byte memori internal ditambah beberapa register (SFR), juga mengalamati hingga $64 \mathrm{~K}$ memori ekternal untuk data.

Secara fisik AT89S51 memiliki jumlah 40 pin. Yaitu port untuk input/output sebanyak 32 pin, yang terdiri dari 8 pin sebagai port 0 yaitu pin 32 sampai dengan pin 39,8 pin sebagai port 1 yaitu pin 1 sampai dengan pin 8,8 pin sebagai port 2 yaitu pin 21 sampai dengan pin 28 dan 8 pin sebagai port 3 yaitu pin 10 sampai dengan pin 17. Khusus untuk port 1 (pin 6, 7, dan 8) digunakan sebagai port ISP (In-System Programable) ditambah dengan port 9 yang berfungsi sebagai reset. ISP ini berfungsi untuk mengisikan program secara paralel ke mikrokontroler. Khusus untuk port 0 pada saat verifikasi program diperlukan external pull-ups pada kedelapan pinnya.

Motor DC tidak dapat dikendalikan secara langsung oleh mikrokontroler, karena kebutuhan arus listrik yang besar pada motor DC sedangkan arus keluaran pada mikro sangat kecil. Driver motor merupakan pilihan alternatif yang harus digunakan untuk mengendalikan motor DC pada robot beroda.

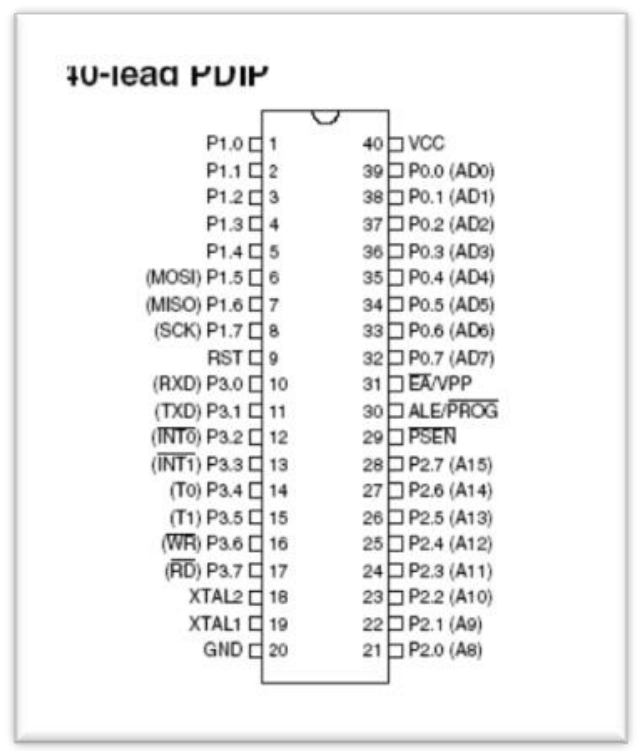

Gambar 2. Konfigurasi pin AT89S51

Ada beberapa drivermotor yang sering digunakan pada aplikasi robotika, yaitu menggunakan rangkaian $\mathrm{H}$-Bridge transistor, H-Bridge MOSFET, dan IC driver motor. Pada tulisan ini saya akan coba membuat tentang rangkaian IC driver motor L298 dan H-bridge Mosfet. Tapi sebelum ke rangkaian driver motor DC saya akan membahas sedikit tentang motor DC. Motor DC adalah suatu piranti elektronik yang befungsi untuk mengubah energi listrik menjadi energi mekanik. Pada aplikasi robotika pergerakan robot beroda umumnya menggunakan motor DC sebagai alat penggeraknya, karena jenis motor ini lebih mudah untuk dikendalikan. Kecepatan yang dihasilkan oleh motor DC berbanding lurus dengan potensial yang diberikan.

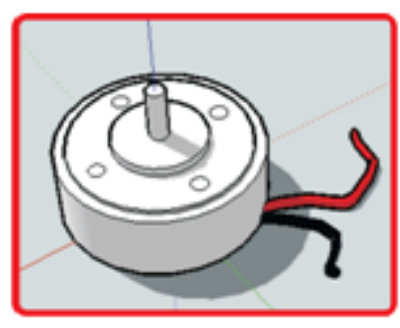

Gambar 3. Motor DC 
Pengaturan arah putaran motor dilakukan dengan mengubah arah polaritas yang mengalir melalui motor. Secara sederhana seperti yang terlihat pada (Gambar 2) hal ini dapat dilakukan dengan mengubah polaritas tegangan motor.

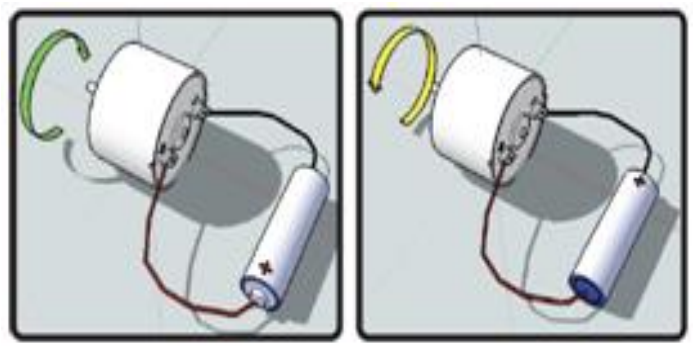

Gambar 4 Pengaturan arah putaran motor DC

Kecepatan motor DC dapat diatur dengan beberapa cara, yaitu dengan mengatur fluks medan, dengan mengatur tahanan jangkar, dan dengan mengatur tegangan sumber. Cara yang ketiga ini merupakan pengaturan yang sering digunakan karena penggunaannya yang relatif mudah (Zuhal, 2004). Pengaturan tegangan sumber biasanya menggunakan metode PWM (Pulse Width Modulation).

LED Infra Merah merupakan salah satu jenis LED (Light Emiting Diode) yang dapat memancarkan cahaya infra merah yang tidak kasat mata. Cahaya infra merah merupakan gelombang cayaha yang berapa pada spectrum cahaya tak kasat mata. LED infra merah dpat memacarkan cahaya infra merah pada saat diode LED ini diberikan tegangan bias maju pada anoda dan katodanya. LED infra merah ini dapat memancarkan gelombang cahaya infra merah karena dibuat dengan bahan khusus untuk memendarkan cahaya infra merah. Bahan pembuatan LED infra merah tersebut adalah bahan Galium Arsenida (GaAs). Secara teoritis LED infra merah mempuyai panjang gelombang $7800 \AA$ dan mempuyai daerah frekuensi 3.104 sampai $4.104 \mathrm{~Hz}$. Dilihat dari jangkah frekuensi yang begitu lebar, infra merah sangat fleksibel dalam pengunaanya. LED ini akan menyerap arus yang lebih besar dari pada dioda biasa. Semakin besar arus yang mengalir maka semakin besar daya pancarnya dan semakin jauh jarak sapuannya.

Cahaya infra-merah tidak mudah terkontaminasi atau teresonan dengan cahaya lain, sehingga dapat digunakan baik siang maupun malam. Aplikasi dari LED infra merah ini dapat digunakan sebagai transmitter remote control maupun sebagai line detektor pada pintu gerbang maupun sebagai sensor pada robot. Aplikasi cahaya infra merah sendiri dapat digunakan sebagai link pada jaringan telekomunikasi atau dapat juga dipancarkan pada fiber optic. Sebagai receiver cahaya infra merah dapat digunakan foto dioda, fot transistor maupun modul receiver infra merah.

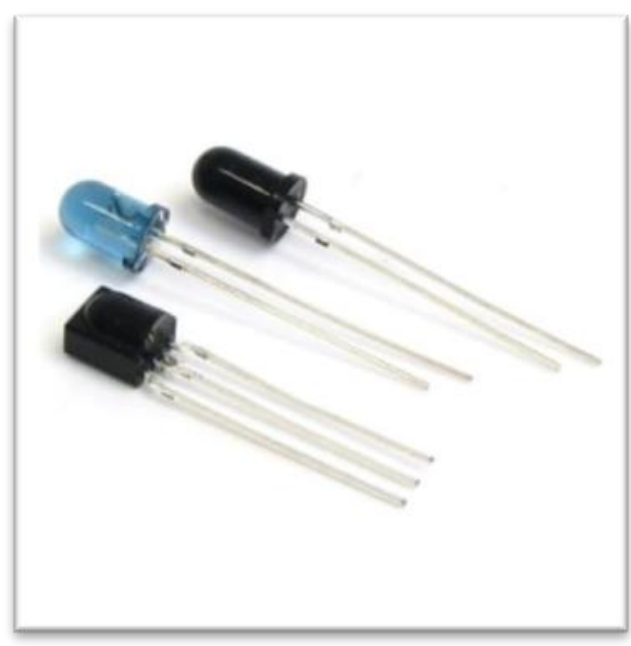

Gambar 5 Bentuk LED Infra Merah

Power Supply adalah perangkat keras yang berfungsi untuk menyuplai tegangan langsung kekomponen dalam casing yang membutuhkan tegangan, misalnya motherboard, hardisk, kipas, dll. Input power supply berupa arus bolak-balik (AC) sehingga power supply harus mengubah tegangan AC menjadi DC (arus searah), karena hardware komputerhanya dapat beroperasi dengan arus DC. Power supply berupa kotak yang umumnya diletakan dibagian belakang atas casing.

Fungsi Power Supply dalam komponen komputer sangat vital, karena power supply merupakan pembagi arus untuk semua perangkat khususnya 
motherboard. Power Supply berfungsi untuk mengubah tegangan dari arus AC menjadi tegangan DC, itu di karenakan hardware di dalam komputer hanya dapat beroperasi dengan arus DC. Pengertian dari power supply adalah sebuah perangkat yang terdapat di dalam CPU yang berfungsi untuk menyalurkan arus listrik ke berbagai peralatan komputer. Fungsi power supply yang kurang baik/rusak dapat menghasilkan tegangan DC yang tidak rata dan banyak riaknya (ripple).

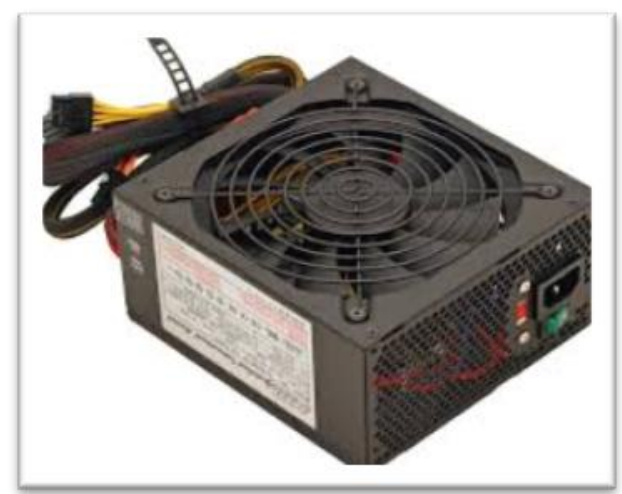

\section{Gambar 6 power supply}

Komponen aktif merupakan komponen yang tidak dapat bekerja tanpa adanya sumber tegangan. Komponen aktif terdiri dari dioda, transistor, IC dan semua jenis komponen semi konduktor lainnya

Transistor memiliki tiga titik penyambungan: basis, emitor dan kolektor. Ada transistor bertipe NPN dan transistor PNP. Pada transistor NPN maka emitornya selalu ditempatkan pada tegangan yang lebih negatif daripada kolektornya. Pada transistor tipe PNP ditempatkan pada tegangan yang lebih positif daripada kolektornya. Suatu arus lemah yang mengalir dari basis ke emitor, akan menimbulkan arus yang (jauh) lebih besar dari kolektor dan emitor. Dengan masukan arus basis yang lemah akan mengaktifkan arus kolektor yang lebih besar bergantung pada faktor penguatan (hfe).

Sebagian besar IC dirakit dalam rumah"DIL" (dual-in-line), pembacaan pin pada IC ditandai dengan titik atau ukiran (dengan pahat).

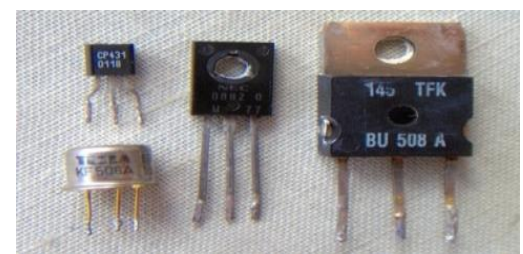

Gambar 7 Transistor

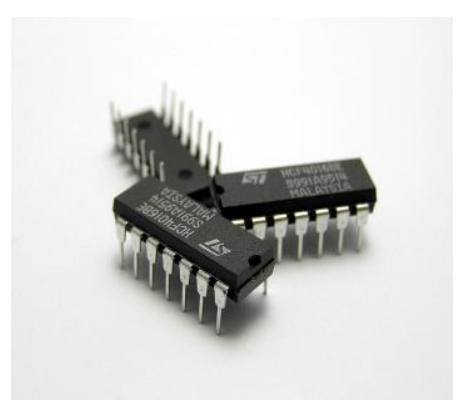

\section{Gambar 8 IC (Intergrated Circuit)}

Komponen pasif merupakan komponen yang dapat bekerja tanpa sumber tegangan. Komponen pasif terdiri dari Hambatan atau tahanan (resistor), kapasitor atau kondensator, induktor atau kumparan.

Resistor merupakan komponen yang paling banyak digunakan pada pirantipiranti elektronik. Sifat listriknya yang paling penting adalan nilai resistansinya. Resistor dalam rumus atau dalam skema ditulis dengan notasi huruf ' $R$ ', dan resistansinya dinyatakan dalam ohm (ditulis $\Omega$ ). Selain resistansi, resistor juga mempunyai tariff daya (watt), yaitu daya maksimum yang boleh melewati hambatan resistor. Ada beberapa jenis daya resistor antara lain $1 / 8 \mathrm{~W}, 1 / 4 \mathrm{~W}, 1 / 2 \mathrm{~W}, 1 \mathrm{~W}, 2 \mathrm{~W}$, $5 \mathrm{~W}, 10 \mathrm{~W}$ dan $20 \mathrm{~W}$.

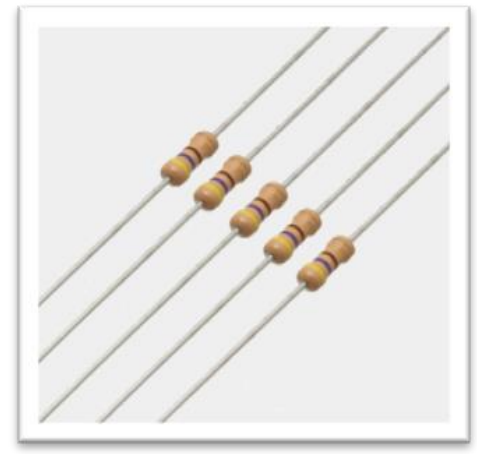

Gambar 9 Resistor 
Di alam rangkaian resistor berfungsi untuk mengurangi arus yang akan dipakai pada komponen yang terhubung seri dengan resistor. Beberapa jenis resistor antara lain resistor tetap, resistor variable, resistor peka cahaya (LDR) dan resistor peka suhu (Thermistor).

Kondensator merupakan tempat penyimpanan muatan listrik dalam ukuran kecil. Kondensator meneruskan tegangan bolak-balik tetapi tidak meneruskan tegangan rata sehingga kendensator juga dipergunakan untuk memindahkan/mengtransportasikan

tegangan bolak-balik. Mengenai jumlah muatan yang dapat ditampungnya, atau kapasitasnya, diukur dalam satuan Farad(F). Nilai dari kondensator-kondensator yang biasa (kondensator keramik dan foli) besarnya $1 \mathrm{pf}$ dan $1 \mathrm{uF}$, jadi antara $1 /$ 1.000.000.000.000 F dan 1 / 1.000.000 F. Pada umumnya, nilainya sering dicantumkan seperti $1 \mathrm{n} 5=1,5 \mathrm{nF} ; 0,03 \mathrm{uF}=$ $30 \mathrm{nF} ; 100 \mathrm{P}($ atau n100 atan n1 $)=100 \mathrm{pF}$. Selain kapasitas, tegangan juga penting diperhatikan, setidak-tidaknya besarnya harus $20 \%$ di atas tegangan pengadaan.

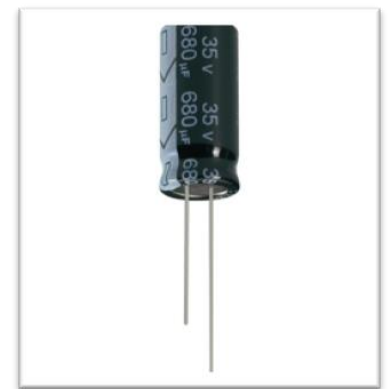

Gambar 10 Kondensator

Dioda merupakan bentuk paling sederhana dari semikonduktor (setengah penghantar listrik). Dioda menghantarkan arus listrik dalam satu arah. Jika dibalik maka dioda akan menyumbat arus. Pada penghantar antara titik-titik sambungan dari dioda silicon akan terjadi tegangan sekitar 0,6 Volt (tegangan-ambang). Ujungujungnya disebut katoda (bersimbol garis lurus) dan anoda. Seringkali katoda dalam rumah katoda diberi tanda berupa cincin berwarna, suatu titik atau suatu takikan.
Data teknis yang terpenting dari suatu dioda adalah tegangan penyumbat dan arus maksimum menurut arah-penghantar. Pada dioda In4148 (tegangan 75 Volt, arus hantar 200mA). IN4001 (tegangan penyumbat 50 Volt,arus-hantar 1A).

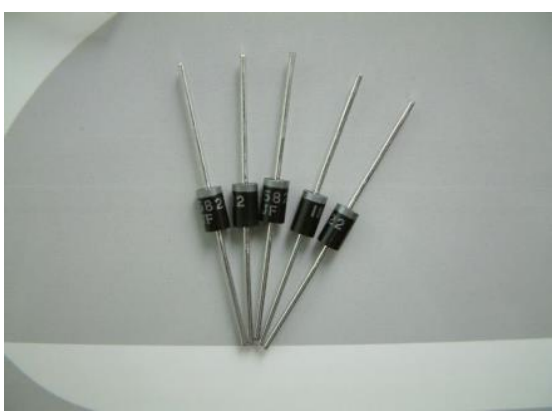

Gambar 11 Dioda

Led (Light Emitting Diodes) adalah dioda yang ditempatkan dalam suatu wadah yang tembus-pandang, yang akan menyala bila dialiri dengan arus listrik. Tegangan yang melalui dioda ini besarnya antara 1,6 Volt dan 2,4 Volt yang ditentukan oleh tipe-tipenya. Arus yang dibutuhkan adalah sebesar 15 sampai $25 \mathrm{~mA}$. Katoda (simbolnya garis lurus) dapat dikenali karena kakinya yang lebih pendek.

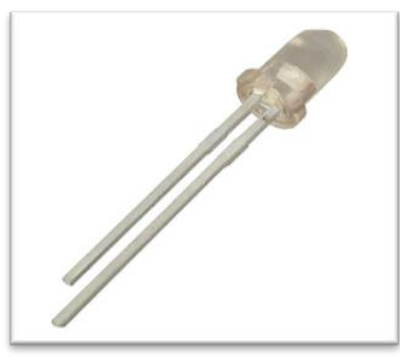

Gambar 12 LED (Light Emitting Diodes)

Adalah resistor khusus dengan kontak-geser yang dapat diatur/disetel. Dengan mengeser kontak-geser ini akan didapat nilai resistansi tertentu yang terdapat pada suatu percabangan. Terdapat resistor variable yang dapat diatur dengan obeng disebut trimport dan resistor variable yang dapat distel langsung pada porosnya disebut potensiometer.

Transformator mengubah sustu tegangan bolak-balik menjadi tegangantegangan yang lebih rendah atau lebih 
tinggi. Transformator terdiri dari gulungan primer dan gulungan sekunder.

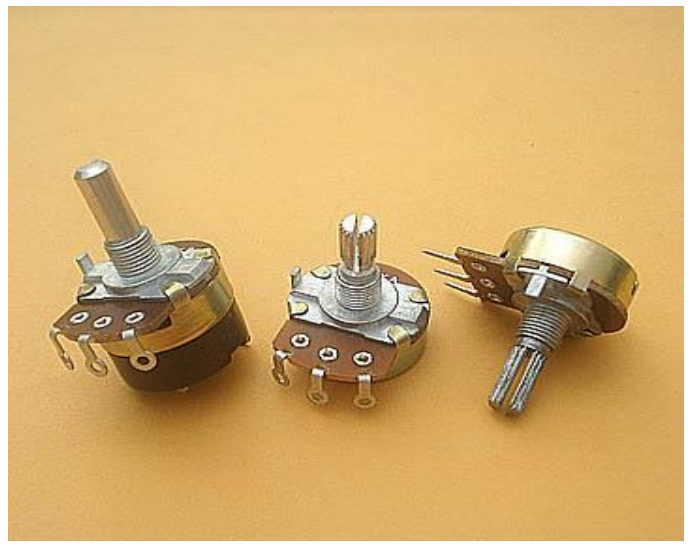

Gambar 13 Potensiometer

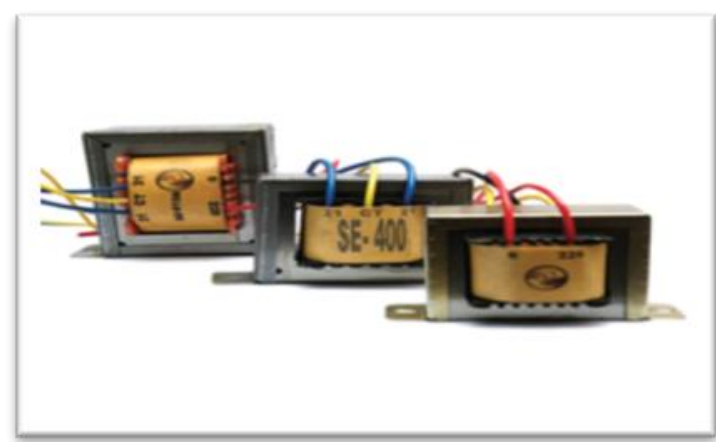

Gambar 14 Trafo

Relay berfungsi untuk memutus atau menghubungkan sirkit dari jarak-jauh, koneksi relay dibedakan menjadi relay dengan kontak-nutup, relay dengan kontakbuka dan relay dengan dua kutup (bi-polar).

Sifat-sifat relay berdasarkan hambatan kumparannya ( 1- $50000 \mathrm{ohm}$ ), Arus yang mengalir melewati kumparan relay, tegangan kerja kumparan relay dan daya yang dibutuhkan untuk menggerakkan kumparan relay.

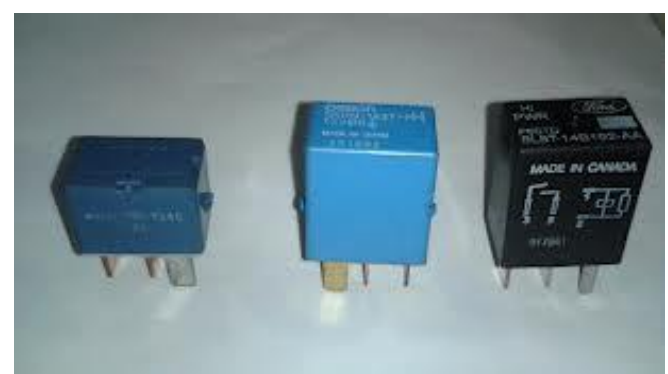

Gambar 15 Relay
Hambatan pada LDR(Light Dependent Resistor) bergantung pada kuat lemahnya cahaya pada permukaan LDR. Jika cahaya yang jatuh pada permukaan LDR kuat, maka nilai resistansinya akan turun, dapat merosot sampai 100 ohm. Demikian sebaliknya dalam gelap gulita nilai resistansinya akan tinggi sekali, dapat mencapai 10 Mohm.

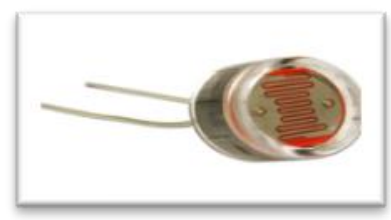

\section{Gambar 16 LDR (Light Dependent Resistor)}

Resistor peka suhu disebut juga thermistor dibedakan menjadi dua macam yaitu NTC (Negative temperature coefficient) suatu resistor yang mempunyai koefisien suhu negatif dan PTC (Positive temperature coefficient) suatu resistor yang mempunyai koefisien positif.

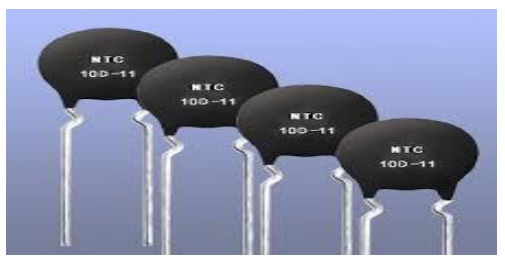

Gambar 17 Thermistor

\section{PERANCANGAN SISTEM}

Dalam perancanganan suatu Conveyor menjadi dasar tumpuan dari rangkaian elektronis dan software kontroler. Konstruksi fisik Conveyordidesain untuk melakukan penyortiran suatu benda berwarna hitam dan putih. Pada alat ini pula terdapat seven segment yang berfungsi sebagai alat hitung benda hitam/putih yang telah tersortir.

Sistem perancangan pemilah benda ini secara umum terdir idari 2 (dua) bagian yaitu :

1. Perancangan perangkatkeras

2. Perancanganperangkatlunak 
Rancangan sistem untuk menjadi sebuah conveyorl alat pemilah benda berdasarkan warna hitam dan putih adalah membuatmasing - masing rangkaian dari bagian sistem dan rancangan konstruksifisik.

Rangkaian elektronis pada "pemilah benda berdasarkan warna(Hitamputih)" ini tergabung dari beberapa modul komponenelektronis yang mempunyai fungsi-fungsi tersendiri sehingga membentuk satu kesatuan sistem kontrol yang dapat menjalankan kontrol dengan dikendalikan oleh software yang dimasukkan kedalam Sistem "pemilah benda berdasarkan warna (Hitam-putih)" tersebut dapat dilihat melaluisebuah diagram blok.

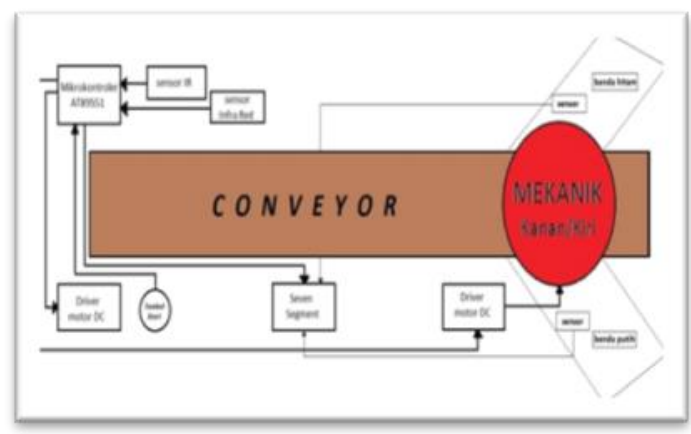

\section{Gambar 18 Blok diagram pemilah benda (hitam dan putih)}

Perancangan Mikrokontroler berfung sisebagai proses dari kesekuruhan sistim, agar IC mikrokontroler dapat bekerjadengan optimal diperlukan beberapa langkah penyambungan terhadap komponen pasi $f$ dan pemberian logika pada pin IC. Pada IC 89S51 terdapatxtall yang besarfrekwensinya dari $3,5 \mathrm{Mhz}$ sampai $12 \mathrm{Mhz}$ yang berfungsi membangkitkan gelombang clock. Pada pin 9 merupakan pin reset yang membutuhkan logikahigh (5V) agar kembali kekeadaan semula. Rangkaian reset terdiridari kapasitor10uf/16V serta resistor $4 \mathrm{k} 7$ yang dihubungkanke ground. Apabilakedua kaki kapasitor dihubungkan makamikrokontroler akan menginisialisasi stack pointer yang akan kembali menunjuk keawal program.

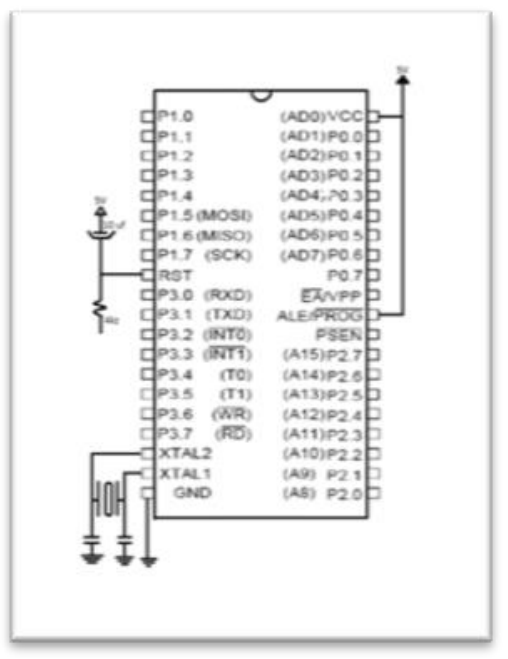

\section{Gambar 19 Mikrokontroler AT89s5}

Oscilator internal dari mikrokontroler 89S51 memiliki 2 pin yaitu $\mathrm{x} 1$ dan $\mathrm{x} 2$, dengan kapasitor 22pf, Oscilator internal ini untuk mengatur program tiaplangkahnya, stabilisasi frekwensi dan juga dalam kecepatan kerjanya. Pin 31 (Ea) pada mikrokontroler dihubungkan keVcc, yang berfungsi agar mikrokontroler mengakses program memory yang berada di dalam mikrokontroler.

Perancangan driver motor ini menggunakan transistor sebagai penggerak dan menentukan arah putaran motor dc, Dengan memberikan logika pada kedua masukan dari driver motor makapergerakan motor dc dapatdikendalikan. Apabila masukan 1 dan masukan 2 diberi logika low $(0 \mathrm{~V})$ maka motor dc akan diam, demikian masukan 1 diberi logika low(0V) sedang masukan 2 diberi high $(5 \mathrm{~V})$ maka motor dc akan bergerak kekiri, Pergerakan motor kekanan terjadi apabila masukan 1 diberi logika high(5V) dan masukan 2 diberilogika low(0V). Modul motor driver akan panas apabila kedua masukan 1 dan masukan 2 diberi logikahigh(5V), hal ini perlu dihindari dengan memberikan logika low pada kedua masukan pada saat inisialisasi awal program.

Pada saat masukan 1 diberi logika maka arus basis akan mengalir melalui resistor 10k menuju ke basis transistor C9013 (Q1), memyebabkan transistor C9013(Q1) menjadiaktif, dan arus 
mengalir dari kolektor C9013(Q1) yang terhubungke basis TIP42C (Q2) sedangkan emitor C9013(Q1) terhubungke basis TIP41C (Q3), hubungan tersebut dibatasi oleh resistor $100 \mathrm{ohm}$ danmembuat Q2 dan Q3 aktif, dan motor bergerak kearah kiri.

Pada saat masukan 2 diberi logika maka arus basis akan mengalir melalui resistor $10 \mathrm{k}$ menuju ke basis transistor C9013 (Q4), memyebabkan transistor C9013(Q4) menjadi aktif, dan arus mengalir darikolektor C9013(Q4) yang terhubung ke basis TIP42C(Q5) sedangkan emitor C9013(Q4) terhubung ke basis TIP41C (Q6), hubungan tersebut dibatasi oleh resistor $100 \mathrm{ohm}$ dan membuat Q5 dan Q6 aktif, dan motor bergerakkearahkanan. Untuk mengatur putaran motor dc dilakukan dengan mengatur trimport $2 \mathrm{~K}$ yang terhubungke basis TIP41C(Q7), dengan di seridengan resistor $100 \mathrm{ohm}$ untuk membentuk rangakaian voltage divider. Tegangan jatuh diantara trimport $2 \mathrm{~K}$ dan trimport $2 \mathrm{~K}$ dikuatkan olehTIP41C(Q7) sehingga dapat diumpankan ke motor dc.

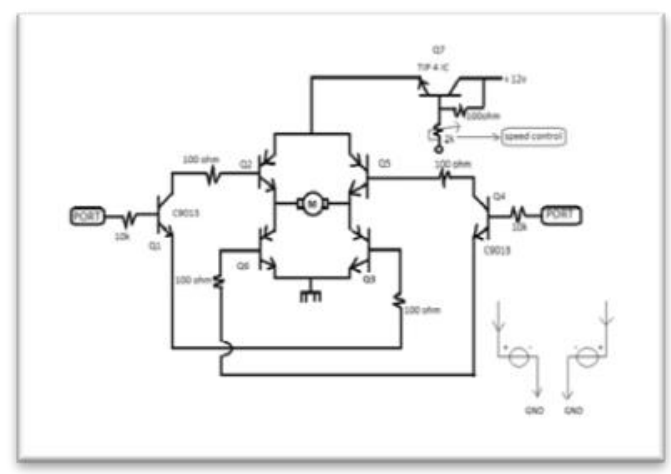

Gambar 20 Rangkaian Driver motor DC

Rangkaian catu daya berfungsi untuk mengubah tegangan $\mathrm{AC} 220 \mathrm{~V}$ dari jala-jala listrik menjadi tegangan DC $5 \mathrm{~V}$ yang akan digunakan untuk menghidupkan rangkaian-rangkaian. Dengan menggunakan trafo 1ACT, tegangan AC220V diubah menjadi tegangan AC9V, karena tegangan masih bersifat AC maka perlu disearahkan dengan dioda IN4002. Setelah melalui dioda IN4002, bentuk gelombang searah tapi masih berupa potongan-potongan gelombang $\mathrm{AC}$ dan mengandung ripple yang besar. Untuk menghilangkan ripple tersebut digunakan kapasitor $1000 \mathrm{uf} / 35 \mathrm{~V}$.

Pada posisi ini tegangan DC yang terbentuk mengikutirumusan 1,414 $\mathrm{X}$ Vin = Vdc, $1,414 \mathrm{X} 9 \mathrm{~V}=12,726 \mathrm{~V}$. Tegangan $12,726 \mathrm{~V}$ ini terlalu tinggi untuk dibebani maka digunakan IC regulator AN7805. Setelah melalui AN7805 ini, tegangan menjadi $5 \mathrm{~V}$ dan untuk menjaga agar tegangan $5 \mathrm{~V}$ ini lebih stabil pada saat akan dibebani, dipergunakan kapasitor 100uf / $16 \mathrm{~V}$.

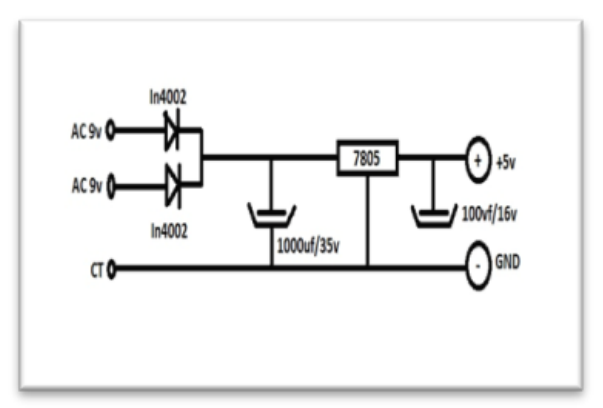

\section{Gambar 21 Rangkaian Power Suplly}

Rangkaian sensor infra merah ini bert ujuan untuk mendeteksi adanya obyek yang melintasiantara led inframerah dengan sensor photodioda. Apabila tidak ada obyek yang melintas maka keluaran modul sensor infra merah ini menjadihigh (5V), demikian sebaliknyaa pabila ada obyek yang melintas maka keluaran menjadi low (0V).

Resistor $100 \mathrm{ohm}$ berfungsi untuk membatasi arus yang masukke led infra merah. Ketika led infra merah menyala, sinarnya terpancar dan diterima oleh photodiode. Pada kondisi tidak ada halangan, photo dioda menjadi aktif dan mengalirkan arus dari trimport $200 \mathrm{~K}$ menujuke ground, mengakibatkan tidak ada arus yang menujuke basis transistor, transistor menjadi tidak aktif, led padam dan keluaran menjadi high (5V).

Pada kondisi ada halangan, photo dioda menjadi tidak aktif dan arus dari trimport 200K tidak menujuke ground, mengakibat kan ada arus yang menuju ke basis transistor, transistor menjadiaktif, led menyaladankeluaranmenjadi low (0V). 


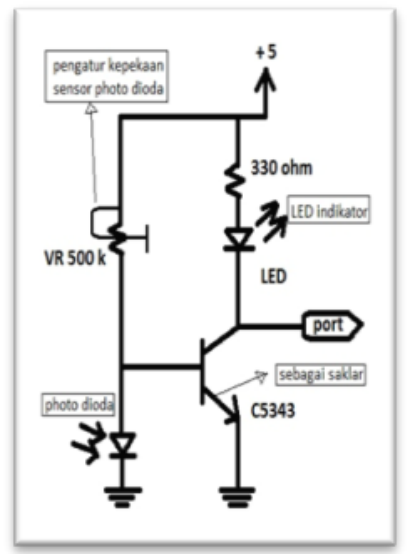

\section{Gambar 22 Rangkaian Sensor InfraRed}

Perancangan driver seven segment berfungsi untuk menampilkan hasil output dari proses mikrokontroler. Display seven segment bekerja dengan menggunakan metode scanning sehingga dapat menghemat catu daya.

Kedua IC4094 berguna untuk mengubah data serial dari port2.2 (strobe), port2.3 (clock) dan port2.4 (data) menjadi data pararel yang terhubung ke a,b,c,d,e,f,g dan dot dari seven segment. Sedangkan scanning display dilakukanoleh 4 buah transistor A103 yang terhubungke common anoda dari masing-masing seven segment.

Alat pemilah benda berdasarkan warna (hitam dan putih) menggunakan sensor InfraRed dan photo dioda yang berfungsi sebagai pedeteksi suatu benda yang melewatinya sedangkan photo dioda sebagai pengatur kepekaan warna. Penggerak pada alat pemilah benda ini menggunakan 1 buah motor dc dan seven segment sebagai alat hitung benda yang telah tesortir.

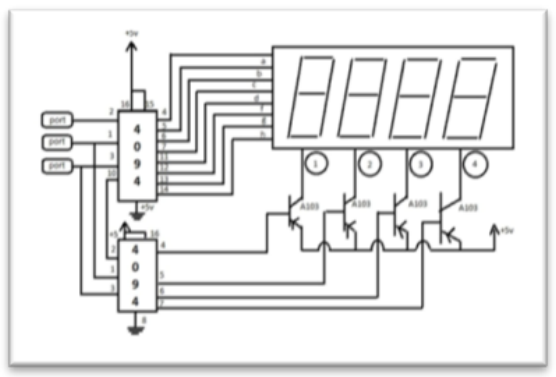

Gambar 3.6 Rangkaian Seven Segment

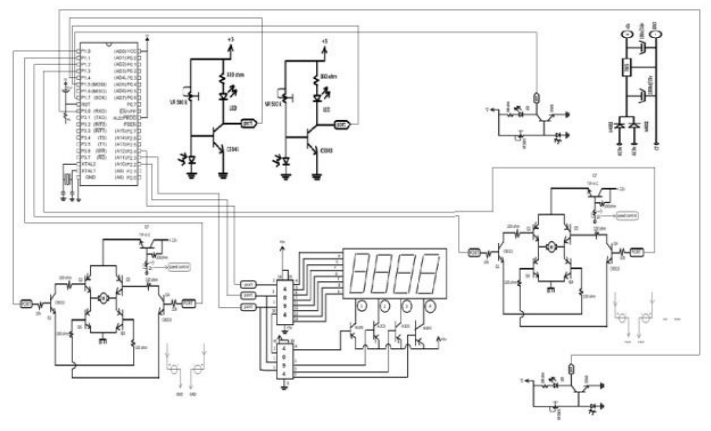

Gambar 23. Rangkaian keseluruhan manufaktur pemilah benda (Hitam dan putih)

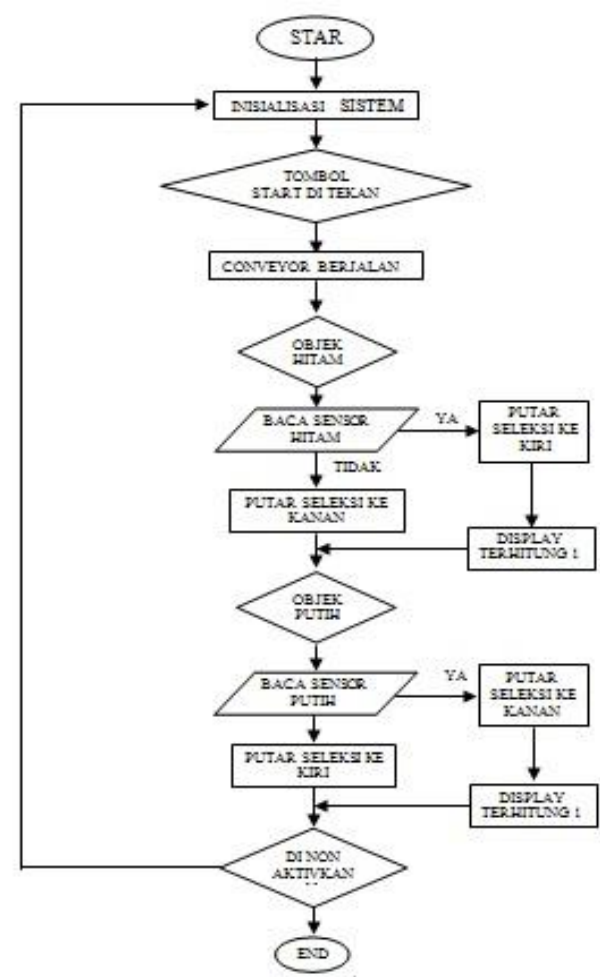

Gambar 24 Flowchart Program

\section{HASIL DAN PEMBAHASAN}

Hasil dari pengujian alat ini akan di jelaskan cara-cara pengoprasian pada simulasi pemilah benda berdasarkan warna (Hitam dan putih). Simulasi pada alat ini berfungsi untuk memilah benda hitam dan putih. Komponen pendukung yang digunakan antara lain Sensor IR dan Driver Motor DC. Bab ini juga menjelaskan cara pengujian yang di lakukan oleh simulasi alat tersebut. 
Cara pengoprasian simulasi pemilah benda berdasarkan warna (hitam dan putih) ini adalah sebagai berikut :

1. Menyalakan alat tersebut dengan cara menyolokan saklar pada fitting listrik.

2. Kemudian lihat apakah alat sudah aktif atau belum,yaitu dengan cara melihat lampu LED pada mikrokontroler AT89S51 menyala atau tidak.

Setelah keseluruhan dibuat dan diuji, maka berikut ini adalah analisa dan hasil pembahasan dari rangkaian kerja alat yang dibuat :

1. Pada saat menghidupkan alat, alat tersebut dalam keadaan ready tetapi belum bisa beroperasi.

2. Menjalankan alat tersebut pertama kali yang harus dilakukan adalah meletakan suatu benda berwarna hitam atau putih pada bagian belakang belt conveyor.

3. Tekan tombol Start pada alat, maka belt conveyor berjalan.

4. Sensor pada alat tersebut akan membaca suatu benda yang melintas di depannya, bila benda tersebut berwarna hitam maka mekanik akan berputar ke kiri dan jika benda tersebut berwarna putih maka mekanik akan berputer ke kanan.

5. Pada saat penyortiran, benda-benda tersebut akan terhitung.

Berikut ini gambar dari hasil pengoprasian dari simulasi pemilah benda berdasarkan warna (hitam dan putih) :

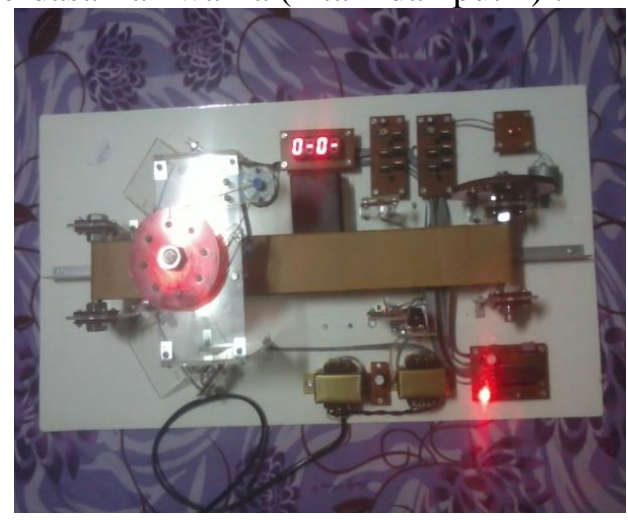

Gambar 25 Simulasi pemilah benda (hitam dan putih)

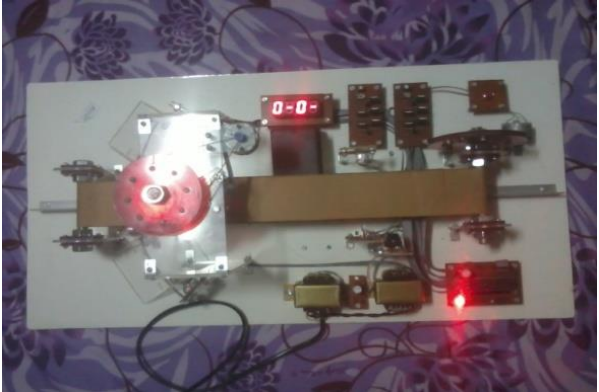

Gambar 26 conveyor dalam keadaan ready

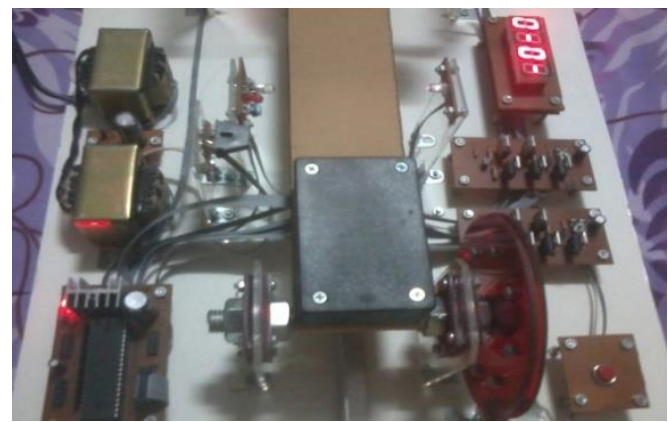

Gambar 27 meletakan benda berwarna hitam

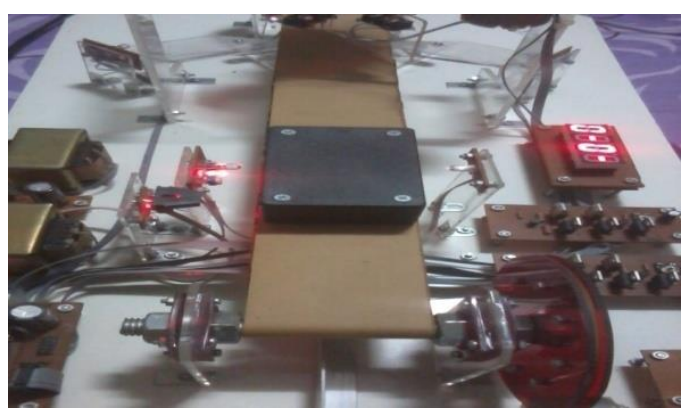

Gambar 28 sensor membaca benda hitam

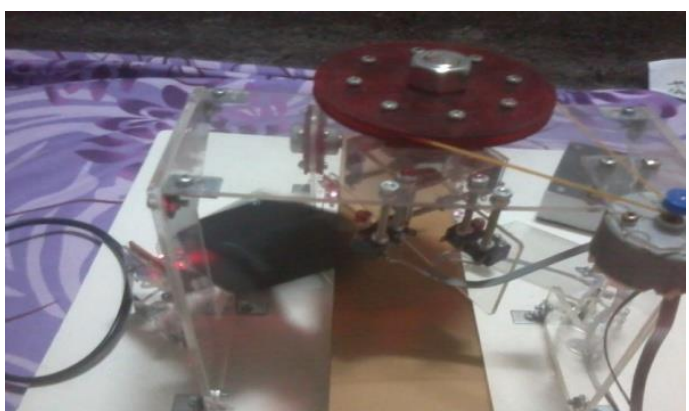

Gambar 29 mekanik benda hitam putar ke kiri 


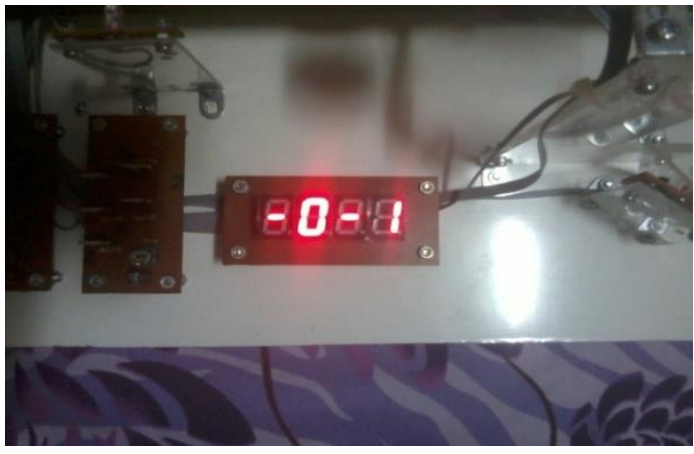

Gambar 30 benda hitam terhitung 1

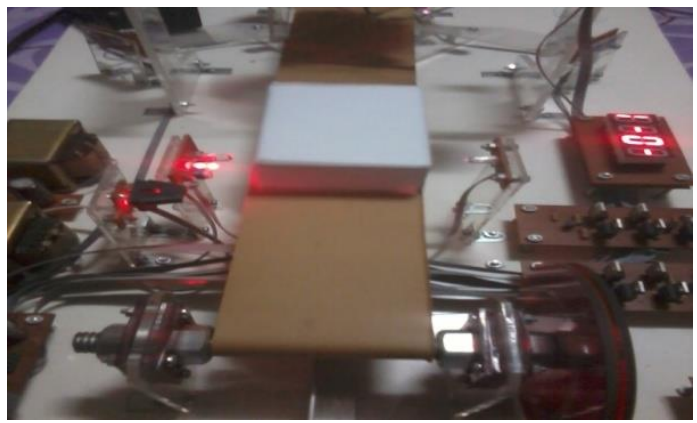

Gambar 31 Sensor membaca benda putih

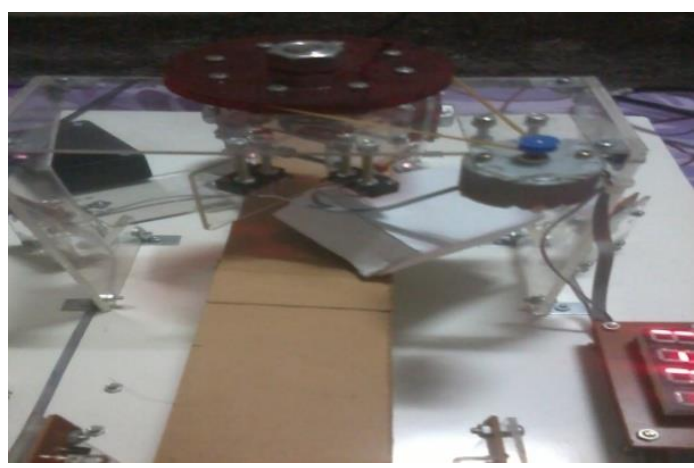

Gambar 32 Mekanik benda putih putar ke kanan

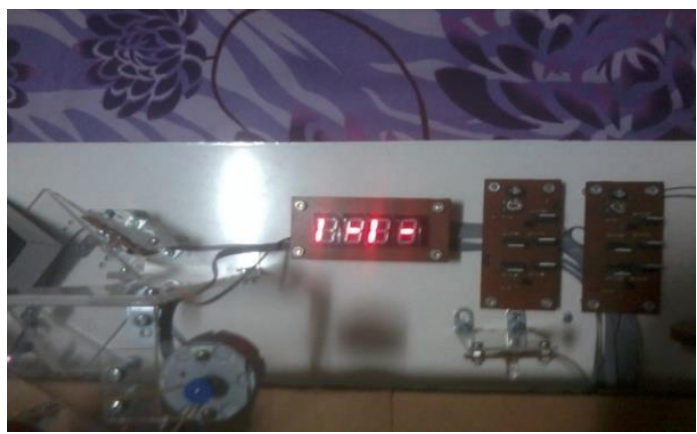

Gambar 33 benda putih terhitung 1
Tabel 1 Pengujian benda hitam dan putih

\begin{tabular}{|c|c|c|}
\hline OBJEK & HITAM & PUTIH \\
\hline HITAM TERSORTIR & 1 & 0 \\
\hline PUTIH TERSORTIR & 1 & 1 \\
\hline HITAM TERSORTIR & 2 & 1 \\
\hline PUTIH TERSORTIR & 2 & 2 \\
\hline HITAM TERSORTIR & 3 & 2 \\
\hline PUTIH TERSORTIR & 3 & 3 \\
\hline HITAM TERSORTIR & 4 & 3 \\
\hline PUTIH TERSORTIR & 4 & 4 \\
\hline HITAM TERSORTIR & 5 & 4 \\
\hline PUTIH TERSORTIR & 5 & 5 \\
\hline HITAM TERSORTIR & 6 & 5 \\
\hline PUTIH TERSORTIR & 6 & 6 \\
\hline HITAM TERSORTIR & 7 & 6 \\
\hline PUTIH TERSORTIR & 7 & 7 \\
\hline HITAM TERSORTIR & 8 & 7 \\
\hline PUTIH TERSORTIR & 8 & 8 \\
\hline HITAM TERSORTIR & 9 & 8 \\
\hline PUTIH TERSORTIR & 9 & 9 \\
\hline
\end{tabular}

\section{KESIMPULAN}

Dari hasil pembahasan dan pengujian alat tersebut, dapat ditarik kesimpulan bahwa simulasi pemilah benda berdasarkan warna hitam dan putih dapat membedakan dan menyortir sebuah benda berwarna hitam dan putih dengan baik.

\section{SARAN}

Dalam pembuatan simulasi ini masih ada kekurangan yang harus diperbaiki, diantara lain:

1. Simulasi ini hanya dapat bekerja dua warna yaitu hitam dan putih maka dari itu bisa dikembangkan lagi untuk dapat memilah benda berbagai warna.

2. Simulasi ini hanya dapat bekerja setiap satu step proses kerja sudah terselesaikan. Maka dari itu, dapat dikembangkan dengan membuat sistem yang terintegrasi yaitu sistem dapat bekerja bila terus ada input benda tanpa harus menunggu proses pertama selesai. 
3. Benda disorting berdasarkan warna yang terdeteksi disensor yang terletak depan sistem sehingga bila terdapat benda warna lain di depannya akan terjadi kekeliruan sorting benda. Untuk mengatasi hal itu, maka dapat menggunakan tambahan sensor warna lagi.

\section{DAFTAR PUSTAKA}

[1] Atmel Corporation. (2006). Datasheet AT89s51

[2] Budiharto, Widodo., Elektronika Digital dan Mikroprosesor, Andi Offset Yoyakarta, 2004.

[3] Budiharto, Widodo., Perancangan Sistem dan Aplikasi Mikrokontroler Elex Media Komputindo, 2005

[4] Budiharto, Widodo., Teknik Interfacing Komputer dan Mikrokontroler Penerbit Elex Media Komputindo, Jakarta 2005
[5] Hall, Douglass, Microprocessor and Interfacing, McGrawHill, USA, 1992

[6] Proakis G, John, Digital Signal Processing, Prentice Hall, 2007

[7] Sigit, Riyanto. (2007). Robotika, Sensor Dan Aktuator. Yogyakarta: Graha Ilmu.

[8] Stalling, William, Data and Computer Communication, Macmilan Publishing Company, New York, 1985

[9] Sunomo. (1996). Elektronika II. Yogyakarta: IKIP Yogyakarta

[10] http://elektronikadasar.web.id/komponen/led-lightemitting-dioda/ 